\title{
The effects of number of conducting switches in a cascaded multilevel inverter output
}

\begin{abstract}
There are three types of multilevel inverter proposed in the early years, namely neutral point clamped or diode clamp multilevel inverter, flying capacitor and cascaded H-bridge multilevel inverter. However, due its modular structure and replicating ability, the cascaded $\mathrm{H}$-bridge multilevel inverter is much more popular and widely improved and modified into various cascaded multilevel inverter topology versions, particularly in the attempts to reduce the total number of switches in the topology design. One aspect that escapes much of the researchers and inventors attention is the effect of the number of conducting switches along the current loop of the inverter before it reaches the output terminals. In this paper, a comparison has been made on the effect of the number of conducting switches during inverter operation between a 41-level classic H-bridge multilevel inverter and a 41-level inverter topology with only one bidirectional switch. Both circuits are tested using Matlab Simulink platform. The results presented show that for higher load power and increased load current, the cascaded $\mathrm{H}$-bridge inverter output is reduced and distorted.
\end{abstract}

Keyword: Multilevel inverter; Neutral line stability; Conducting switch 